\title{
Improved speed response of DC motor via intelligent techniques
}

\author{
Hassan Farhan Rashag \\ Technical Institute of Babylon, Al-Furat Al-Awsat Technical University, Iraq
}

\begin{tabular}{|c|c|}
\hline Article Info & ABSTRACT \\
\hline Article history: & \multirow{9}{*}{$\begin{array}{l}\text { The classical Proportional - Integral (PI) control for Direct Current (DC) } \\
\text { motor causes slow response of actual speed with high overshoot and } \\
\text { undershoot which leads to sluggishness of the system. To minimize the } \\
\text { problem of PI controller, intelligent technique based on hybrid neural } \\
\text { network sliding mode control NN-SMC is suggested. The benefits of SMC } \\
\text { are that it is simple, and tough to parameter deviations as compared with } \\
\text { other controllers. In this paper, the neural network NN is used to minimize } \\
\text { the error between reference speed and actual speed. In addition, the SMC aim } \\
\text { is to control and optimize the voltage that is supplies the DC motor which } \\
\text { guarantees the robust performance of the speed controller under disturbances. } \\
\text { The proposed method for the speed control is first calculated and executed to } \\
\text { DC motor by using MATLAB SIMULINK. The results of the suggested NN- } \\
\text { SMC are compared with the traditional PI controller. The results obviously } \\
\text { show the supremacy of NN-SMC over PI controller. }\end{array}$} \\
\hline Received Apr 29, 2019 & \\
\hline Revised Jun 20, 2019 & \\
\hline Accepted Jul 5, 2019 & \\
\hline Keywords: & \\
\hline DC motor & \\
\hline Neural network (NN) & \\
\hline Sliding mode control (SMC) & \\
\hline PI controller & \\
\hline
\end{tabular}

Copyright $(2019$ Institute of Advanced Engineering and Science. All rights reserved.

\section{Corresponding Author:}

Hassan Farhan Rashag, Technical Institute of Babylon, Al-Furat Al-Awsat Technical University, Kufa, Irak.

Email: Hassan_rashag@yahoo.com

\section{INTRODUCTION}

DC motor is commonly used in manufacturing uses because of its dependability. Many researchers suggested methods to control the speed of DC motors. PI controller is used for adjusting the speed of DC motor and implemented in Field-Programmable-Gate-Array (FPGA) [1]. Fuzzy controller was proposed to control the speed of DC motors based on feedback [2]. The real systems were controlled by SMC because of its robustness and simplicity [3]. Thus, these SMC with fuzzy logic controller was suggested to control the DC servo motors dynamic of sensors [4, 5]. New approaches of two SMC were employed for angular velocity of DC motor [6]. Speed of servo motor was enhanced based on discrete SMC [7]. Furthermore, high contribution for control of real systems was recorded based on fractional order SMC [8]. In the nonlinear systems, for multi inputs and multi outputs, the SMC performance was modified via the fractional order SMC [9]. In addition, the fractional-order sliding surface is used to decrease the distortion of speed [10]. The effectiveness of fractional order SMC for speed of a PMSM [11] and position of a DC motor is also confirmed [12]. The main purpose of PI controllers is to control the speed. However, due to parameter deviations of nonlinear system, PI controller is unable to adjust the speed. SMC is designed for control the speed of permanent magnet DC motor based on fractional order to minimize the load disturbance and parameters variations $[13,14]$.

In the current paper, new approach for optimize the speed of a DC motor is suggested based on hybrid intelligent NN-SMC. In addition, the aim of NN is to decrease the error between the desired speed and actual speed through back propagations BP. Also, the SMC is used to adjustable the voltage which supplies the DC motor. from simulation results, it can be noted that the intelligent technique based on NN-SMC is robustness for nonlinear system. 


\section{MATERIAL AND PROPOSED METHOD}

This proposed method is built by using Matlab Simulink with toolbox. The classical control of DC motor based on PI controller is suffered from overshoot, undershoot, and slow response of speed which degrades the system performance. In order to overcome this problem, hybrid technique based on neural network with sliding mode control is suggested. Here, the reference speed and actual speed are the inputs to $\mathrm{NN}$ and the error is the output. This error with change of error will apply to SMC to generate the voltage that supply the DC motor. The simulink of NN with SMC is shown in Figure 1.

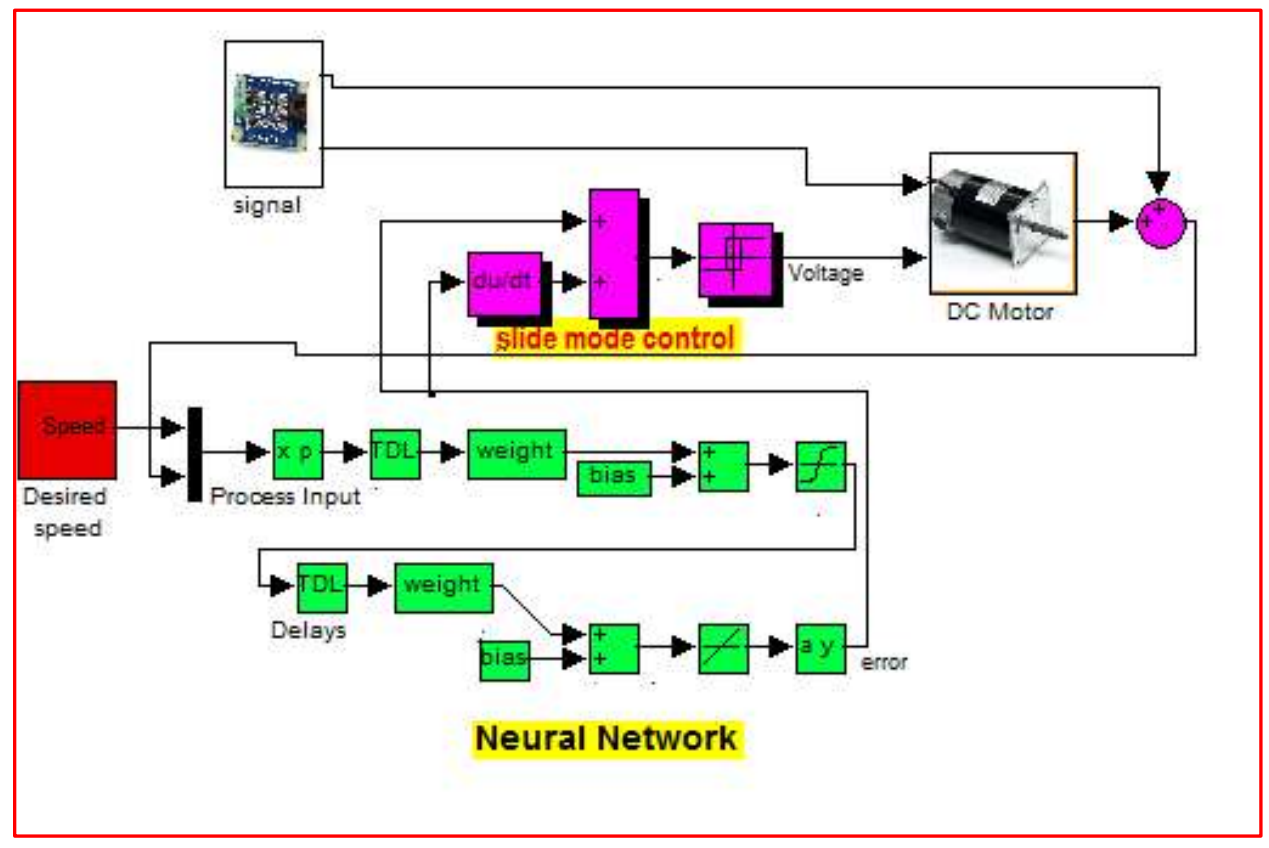

Figure 1. Simulink of NN with SMC

\section{THE SIMULATION RESULTS AND DISCUSSION}

From Figure 2 and Figure 3, the speed of DC motor through NN-SMC is good tracking with reference speed and fast response. In contrast, the speed based on classical PI controller has overshoot and under shoot with slow response.

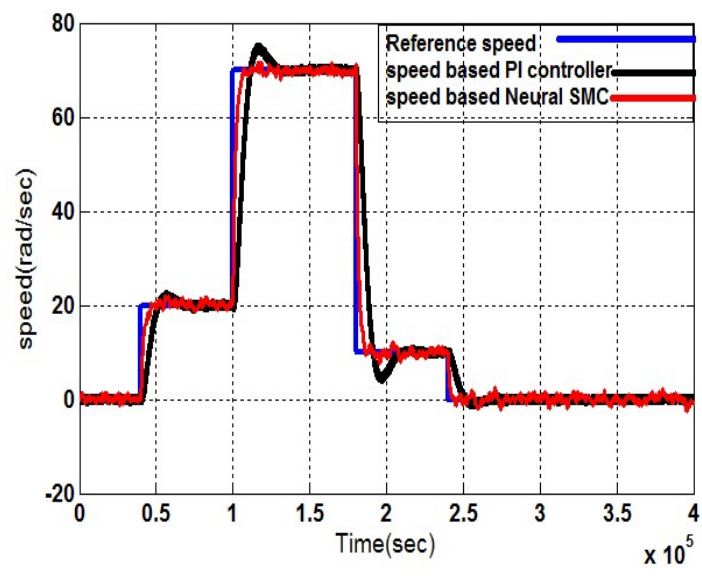

Figure 2. Comparison of speed

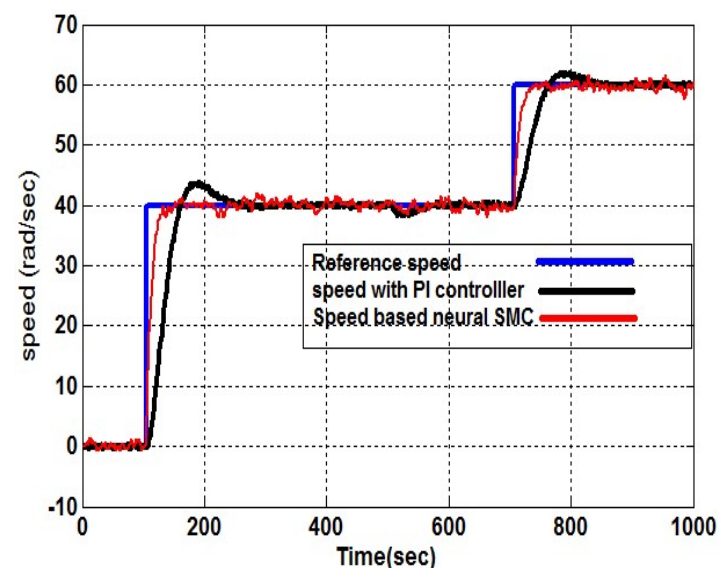

Figure 3. Response of actual speed with reference speed 
Figure 4 shows the robustness of voltage based NN-SMC with variation of reference speed but the voltage of classical PI controller is unstable. From Figure 5 when the load torque is applied on DC motor, the performance of PI speed response is deteriorating and the effect is obvious while the effect of torque on proposed NN-SMC speed is trivial.

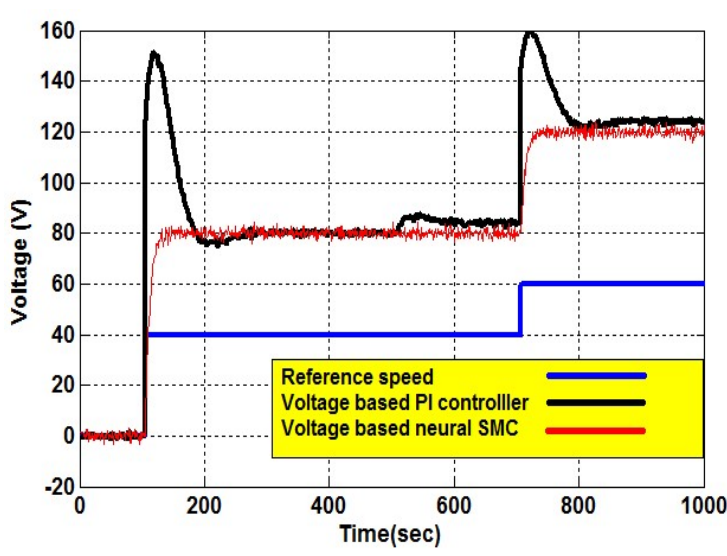

Figure 4. Voltage comparison

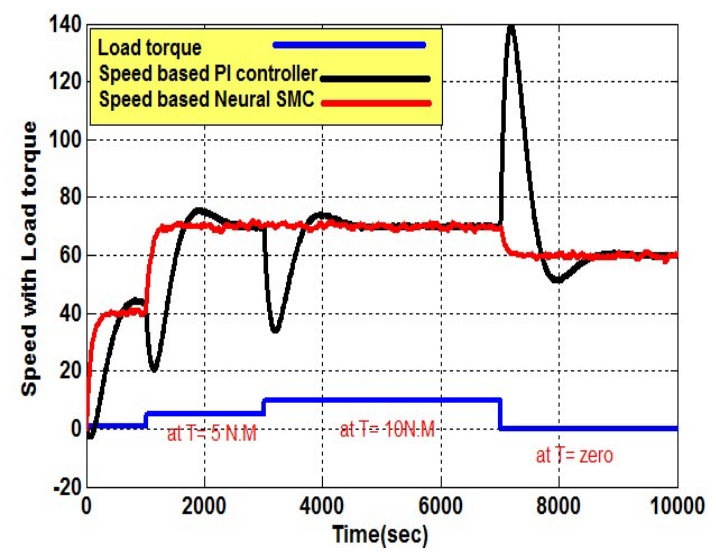

Figure 5. Speed response with variation of load torque

The error between the actual speed and reference speed of proposed NN-SMC is almost approach to zero as shown in Figure 6. Furthermore, the error of classical PI controller is fluctuating between 40rad/sec to $30 \mathrm{rad} / \mathrm{sec}$ which caused instability of system.

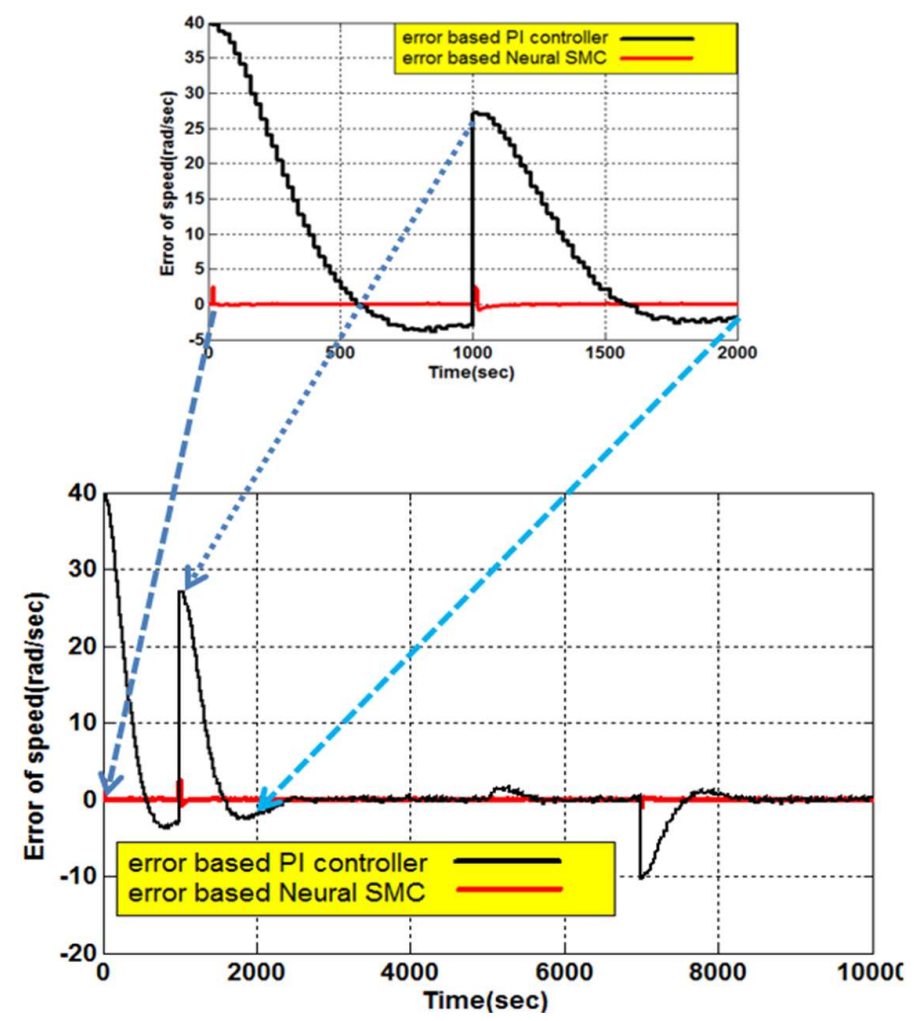

Figure 6. Comparison the error of speed 


\section{CONCLUSION}

This proposed method exhibits an enhanced control for speed of DC motor using intelligent technique NN-SMC. The PI controller can be used for regulating the speed but it needs long time to reach the steady state due to overshoot and undershoot. Therefore, the PI controller is replaced by the intelligent NNSMC to modify the system. The NN-SMC gave better performance under load disturbances as compared with PI controller. Finally, the system with NN-SMC is more accuracy, fast response of speed, and low effect under parameters variation condition.

\section{REFERENCES}

[1] C. F. Hsu and B. K. Lee, "FPGA-based adaptive PID control of a DC motor driver via sliding-mode approach," Expert Syst. Appl., vol. 38, pp. 11866-11872, Sept. 2011.

[2] G. G. Rigatos, "Adaptive fuzzy control of DC motors using state and output feedback," Electr. Pow. Syst. Res., vol. 79, pp. 1579-1592, Nov. 2009.

[3] A. Pisano and E. Usai, "Sliding mode control: A survey with applications in math," Math. Comput. Simulat., vol. 81, pp. 954-979, Jan. 2011.

[4] J. X. Xu, T. H. Lee, and Y. J. Pan, "On the sliding mode control for DC servo mechanisms in the presence of unmodeled dynamics," Mechatronics, vol. 13, pp. 755-770, Sept. 2003.

[5] J M. J. Knight and R. Sutton, "Fuzzy model based sliding-mode control of a d.c. servomechanism," P. I. Mech. Eng. I-J. Sys., vol. 218, pp. 211- 225, May 2004.

[6] A. Susperregui, G. Tapia, and A. Tapia, "Application of two alternative sliding-mode control approaches to DC servomotor position tracking," IET Electr. Power Appl., vol. 1, pp. 611-621, July 2007.

[7] C. Milosavljevic, B. Perunicic-Derazenovic, and B. Veselic, "Discretetime velocity servo system design using sliding mode control approach with disturbance compensation," IET Trans. Industr. Inform., vol. 9, pp. 920-927, May 2013.

[8] I. Podlubny, Fractional Differential Equations. San Diego, CA, USA: Academic Press, 1999.

[9] M. O. Efe and C. Kasnakoglu, "A fractional adaptation law for sliding mode control," Int. J. Adapt. Control Signal Process., vol. 22, pp. 968-986, Dec. 2008.

[10] M. L. Corradini, R. Giambo, and S. Pettinari, "On the adoption of a fractional-order sliding surface for the robust control of integer-order LTI plants," Automatica, vol. 51, pp. 364-371, Jan. 2015.

[11] B. Zhang, Y. Pi, and Y. Luo, "Fractional order sliding-mode control based on parameters auto-tuning for velocity control of permanent magnet synchronous motor," ISA Trans., vol. 51, pp. 649-656, Sept. 2012.

[12] W. Khan, "A comparison between integer and fractional order algebraic approaches for on-line parameter estimation and position control of DC motor," 11 th International Bhurban Conference on Applied Sciences and Technology, Islamabad, pp. 103-107, 2014.

[13] Vadim Utkin, Jürgen Guldner, and Jingxin Shi, Sliding Mode Control in Electro-Mechanical Systems. CRC Press Boca Raton, 2009.

[14] Saeed Heidarpoor, Hamed Khodadadi, and Mohammad Tabatabaei, "Speed control of a DC motor using a fractional order sliding mode controller" IEEE International Conference on Environment and Electrical Engineering and 2017 IEEE Industrial and Commercial Power Systems Europe (EEEIC / I\&CPS Europe), 2017. 